\title{
Phosphorus Leaching in Sandy Soils. I. Short-term Effects of Fertilizer Applications and Environmental Conditions
}

\author{
D. M. Weaver, G. S. P. Ritchie, G. C. Anderson and D. M. Deeley
}

\begin{abstract}
The consequences of previous as well as current environmental conditions and management practices on the potential for phosphorus $(P)$ to be lost by drainage from sandy soils in the short term ( $<1$ year) were studied in the laboratory and the field. The potential for $P$ losses by drainage was estimated by measuring soil solution $P$ levels and rapidly released $P$. Rapidly released $P$ was measured by determining the concentration of dissolved inorganic $P$ contained in filtered $(<0.45 \mu \mathrm{m})$ soil solutions after incubating soil at saturation for $15 \mathrm{~min}$ at ambient temperature. In the laboratory, sandy soils were incubated with ordinary superphosphate, coastal superphosphate (a granulated mixture of equal parts of superphospate, rock phosphate and elemental sulfur) or lime-superphosphate (a lime-reverted superphosphate with $18 \%$ kiln dust) and sequentially desorbed with deionized water. The effects of the extent of leaching, fertilizer type, application rate and the time of contact with the soil on soil solution $P$ levels were investigated. The influence of annual pasture death and summer rainfall on rapidly released $P$ in soils that had been pre-treated by leaching were also investigated.

Phosphorus concentrations decreased logarithmically in the successive supernatants of the sequentially desorbed soils. More $\mathrm{P}$ was desorbed from soils incubated with superphosphate and lime-superphosphate than soil incubated with coastal superphosphate. At each level of pre-leaching, the $\mathbf{P}$ concentrations in the soil solution increased with increasing time. The level, to which the $\mathrm{P}$ concentration in the soil solution increased at each time, decreased with increased extent of pre-leaching. The addition of $P$ fertilizers increased the concentration of $P$ in the soil solution. The concentrations increased with increasing application rate and were much higher for superphosphate than for coastal superphosphate; however, there was little effect of contact time on soil solution $\mathrm{P}$ levels. Rapidly released $\mathrm{P}$ levels after leaching increased during a period of no further leaching. Additional moisture or plant material during this period of no further leaching increased the rate and extent to which rapidly released $P$ increased. Monitoring of rapidly released $P$ in the $0-2,2-5,5-10$ and $10-20 \mathrm{~cm}$ layers of field plots, with and without applications of superphosphate, showed that sampling depth, water flow path, fertilizer management, rainfall pattern and background $P$ levels would affect the estimate of short-term $P$ losses: Rapidly released $P$ in the $0-2 \mathrm{~cm}$ layer varied markedly with time and was higher $(P<0.05)$ than that in lower soil layers. Rapidly released $P$ increased after the winter and spring rains diminished and then decreased after the rains commenced again at the end of the summer. A possible annual cycle of $P$ in sandy soils in a mediterranean climate is postulated by considering the laboratory and field data in combination.
\end{abstract}

\section{Introduction}

Phosphorus (P) losses by drainage (i.e. by leaching and runoff) from soils results in inefficient utilization of fertilizer and increased risk of eutrophication of rivers and estuaries (Berkheiser et al. 1980; Enfield and Ellis 1983). On sandy soils, up 
to $90 \%$ of applied $\mathbf{P}$ from superphosphate may be lost by drainage (Neller 1946; Hingston 1959; Gillman 1973). Birch (1982) showed that about $90 \%$ of the $P$ exported to an estuarine system on the south-west coast of Western Australia came from only $28 \%$ of the catchment area. He attributed this $P$ loss to an increase in regular superphosphate applications $\left(18 \mathrm{~kg} \mathrm{Pha}^{-1} \mathrm{yr}^{-1}\right)$ on the sandy soils in the region over the past $40-50$ years. The loss of $P$ from a particular site may vary from year to year even when rainfall levels are similar (Hodgkin et al. 1980), suggesting that factors other than the amount of rainfall may influence $P$ losses. These factors may include soil properties (e.g. adsorption capacity, amount and type of soil P), environmental conditions (e.g. rainfall intensity and temporal distribution of the rainfall) and management practices (i.e. solubility and rate of fertilizer application, time of application relative to rainfall, type of crop).

The potential for $\mathbf{P}$ to be lost depends on the amount of $\mathbf{P}$ which can be rapidly released into the soil solution. Within the context of $\mathrm{P}$ losses by drainage, the forms of $P$ in sandy soils may be arbitrarily divided into two pools based on the rate of release of $\mathbf{P}$ to the soil solution: a pool which slowly releases $\mathbf{P}$ (slowly released $\mathbf{P}$, SRP) and a pool that rapidly releases $P$ (rapidly released P, RRP) (see Scheme 1).

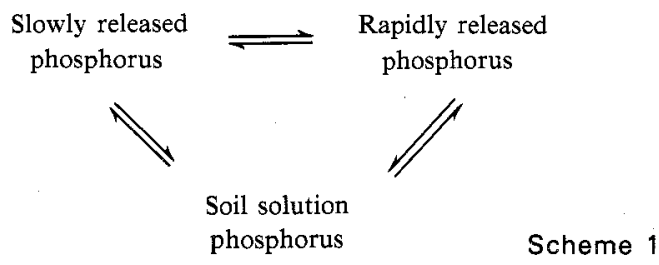

The pools differ in their capacity to supply $P$, and in the rate at which they can maintain that supply, the pools do not necessarily represent a specific type of $\mathbf{P}$ but may consist of inorganic $\mathbf{P}$ (i.e. adsorbed, residual fertilizer compounds or precipitates) or of organic $\mathbf{P}$. The level of $\mathbf{P}$ in these arbitrary pools (SRP, RRP) is constantly changing in response to inputs from fertilizers and plant death, and to outputs by drainage and plant uptake.

The objectives of these studies were to investigate the consequences of previous as well as current management practices and environmental conditions on the potential for $P$ to be lost from sandy soils in the short term (i.e. during one year only). Rapidly released $\mathbf{P}$ was used as an estimate of the potential of a soil to lose $\mathbf{P}$ and was measured by determining the concentration of dissolved inorganic $\mathbf{P}$ contained in filtered $(<0.45 \mu \mathrm{m})$ soil solution after incubating soil at saturation for $15 \mathrm{~min}$ at ambient temperature.

Sandy soils, incubated with different fertilizers, were sequentially desorbed with deionized water. The effects of the extent of leaching, fertilizer type, application rate and the time of contact with the soil on soil solution $\mathbf{P}$ levels were investigated. These are factors that may influence $\mathbf{P}$ losses to drainage during the wet winter period of a mediterranean climate. The influence of annual pasture death and summer rainfall (that wets the soil but does not cause drainage) on RRP in soils that had been pre-treated by leaching (to simulate the $P$ status at the end of winter) were also investigated. Annual pasture death and summer rainfall represented factors that occur during the dry, warm summer period of a mediterranean climate that may affect the extent of $\mathbf{P}$ losses when the next wet winter period commences. 
We assessed the importance of each factor individually in the laboratory and then made field measurements to see if the effects of the main factors could be detected.

\section{Materials and Methods}

\section{Soils and Climate}

The soils investigated were typical of the Bassendean Sand Association, in particular the Joel (Uc 2.33, Northcote classification) and Gavin (Uc 2.22) series, and have been described in detail by Bettenay et al. (1960) and McArthur and Bettenay (1960). The soils are siliceous sands, are naturally low in $\mathrm{P}$ and have a very low capacity to adsorb $\mathrm{P}\left(<2.0 \mu \mathrm{g} \mathrm{g}^{-1}\right.$ adsorbed per gram of a virgin soil from a. $10 \mu \mathrm{g} \mathrm{P} \mathrm{ml}-1$ solution shaken for $17 \mathrm{~h}$ at a soil/solution ratio of $1: 20$ ). Typically, a virgin soil contains $<30 \mu \mathrm{g} \mathrm{g}^{-1}$ total $\mathrm{P}$ of which approximately $75 \%$ is organic $\mathrm{P}$. Field capacity moisture is approximately $10 \%$ and wilting point is approximately $4 \%$ for Joel soils. The climate is mediterranean (McArthur and Bettenay 1960) with an average annual rainfall of $1000 \mathrm{~mm}$ and an annual potential evaporation rate of $1300 \mathrm{~mm}$. The mean average temperature is $27.9^{\circ} \mathrm{C}$ during summer (November-April) with the average rainfall during this period being $150 \mathrm{~mm}$. The winter months (May-October) receive an average rainfall of $850 \mathrm{~mm}, 80 \%$ of which falls from May to August. The average maximum temperature during winter is $18.1^{\circ} \mathrm{C}$.

Table 1. The content and solubility of phosphorus in the fertilizers used

\begin{tabular}{lccc}
\hline Fertilizer & $\begin{array}{c}\text { Total P content } \\
\text { (\% of fertilizer) }\end{array}$ & $\begin{array}{c}\text { Water soluble } \\
\text { (\% of total P) }\end{array}$ & $\begin{array}{c}\text { Citrate soluble } \\
\text { (\% of total P) }\end{array}$ \\
\hline Superphosphate & 10.0 & 84 & 9 \\
Lime-superphosphate & 7.2 & 17 & 71 \\
Coastal superphosphate & 9.8 & 20 & 13 \\
\hline
\end{tabular}

\section{Experiment 1. Sequential Desorption}

The effect of continuous leaching and fertilizer type on $P$ levels in solution were simulated by sequential desorption with deionized water. The fertilizers studied were ordinary superphosphate, lime-superphosphate (a lime-reverted superphosphate with $18 \%$ kiln dust) and coastal superphosphate (a granulated mixture of equal parts of superphosphate, rock phosphate and elemental sulfur (Yeates et al. 1984). The $P$ content and solubility of the fertilizers are given in Tabie 1. Each fertilizer was ground $(<180 \mu \mathrm{m})$ and added at the rate equivalent to $18 \mathrm{~kg}$ $\mathrm{P} \mathrm{ha}^{-1}$ to a $10 \mathrm{~cm}$ depth $\left(12 \mu \mathrm{g} \mathrm{g}^{-1}\right)$ to three portions of air-dry virgin Joel soil $(<2 \mathrm{~mm})$. The fertilizers were ground to ensure uniform distribution throughout the soil and to minimize fertilizer particle size effects. Each sample was thoroughly mixed and incubated at field capacity for $90 \mathrm{~h}$ at $50^{\circ} \mathrm{C}$ (equivalent to one month at $20^{\circ} \mathrm{C}$ according to the Arhennius equation; Castellan $1970)$ and then air-dried at room temperature $\left(20^{\circ} \mathrm{C}\right)$. The soils were then subjected to 10 sequential $15 \mathrm{~min}$ extractions with deionized water at solution/solid ratios of $10: 1,5: 1$ and $1: 1$. The samples were centrifuged and the filtered supernatant $(<0.45 \mu \mathrm{m})$ was analysed for dissolved inorganic P by the molybdenum blue method of John (1970).

\section{Experiment 2. Extent of Leaching}

The effect of the extent of prior leaching on changes in soil solution $\mathbf{P}$ levels during subsequent pauses of different intervals was investigated. Air-dry Joel soil $(<2 \mathrm{~mm})$ which had previously been under pasture for 10 years was leached in columns under saturated flow with deionized water for the equivalent of $0,50,200$ or $400 \mathrm{~mm}$ of rainfall. Upon reaching the desired level of leaching, the soil was removed from the saturated columns, and incubated at ambient temperature $\left(20^{\circ} \mathrm{C}\right)$. The soil was subsampled at various times up to 15 days, after which the soil solution was obtained by centrifugation (Gillman 1970), filtered $(<0.45 \mu \mathrm{m})$ and analysed for dissolved inorganic $P$. 


\section{Experiment 3. Fertilizer Type, Application Rate and Time of Contact}

The effect of application rate and the time of contact of superphosphate or coastal superphosphate with Joel soil on the level of $P$ in the soil solution was investigated. The fertilizers were ground $(<180 \mu \mathrm{m})$ and mixed throughout air-dry, virgin Joel soil $(<2 \mathrm{~mm})$ at the rates of $0,1.25,2.5,5,10$ and $20 \mathrm{~kg} \mathrm{Pha}^{-1}$ to a $2.5 \mathrm{~cm}$ depth (equivalent to $0,3 \cdot 3,6.7$, $13.3,26.7$ and $53.3 \mu \mathrm{g} \mathrm{P} \mathrm{g}{ }^{-1}$ ). The soil was wet to saturation, incubated at room temperature $\left(20^{\circ} \mathrm{C}\right)$ and subsampled at 1 and 14 days. The soil solution was then obtained by centrifugation, filtered $(<0.45 \mu \mathrm{m})$ and analysed for dissolved inorganic $P$.

\section{Experiment 4. Effect of Moisture on RRP after Continuous Leaching}

The effect of summer rainfall on rapidly released phosphorus (RRP) during dry warm periods was simulated. Rapidly released phosphorus represents the $\mathbf{P}$ extracted after incubating soil at saturation for $15 \mathrm{~min}$ at ambient temperature, removing the soil solution by centrifugation, and analysing the filtered solution $(<0.45 \mu \mathrm{m})$ for dissolved inorganic P. Air-dry Joel soil $(<2 \mathrm{~mm})$ which had previously been under pasture for 15 years was leached in a column with deionized water by using saturated flow, with the equivalent of $850 \mathrm{~mm}$ of rainfall to simulate the $P$ status of the soil at the end of the wet season and the beginning of summer. The soil was removed from the column and divided into two; a control and a summer rainfall treatment. Each was incubated, initially at $25^{\circ} \mathrm{C}$ and then at $70^{\circ} \mathrm{C}$ to speed up the simulation of the summer period. During incubation, deionized water was added to the summer rainfall treatment soil at intervals designed to simulate summer rainfall events. The timing and volume of the rainfall events were estimated from the total average rainfall for the months November-April $(150 \mathrm{~mm})$ and the average number of wet days per month. No single application was sufficient to cause drainage of water from the soil. The control soil was allowed to dry out completely. Both treatments were subsampled at times equivalent to $4,8,31,87,165$ and 239 days at $27.9^{\circ} \mathrm{C}$ and $R R P$ was determined. Incubation times at each temperature were transformed to incubation times at a constant temperature $\left(27.9^{\circ} \mathrm{C}\right.$ ) by using the Arrhenius equation (Castellan 1970). The validity of this assumption was checked by transforming times at a wide temperature range $\left(25-70^{\circ} \mathrm{C}\right)$ to a constant temperature. The transformed data points were all positioned along the same curve, thus we considered the relationship valid for our purposes. If a 'rainfall event' and subsampling occurred at the same time, the subsampling was carried out immediately prior to the rainfall event.

\section{Experiment 5. Effect of Adding Plant Material after Continuous Leaching on RRP}

The effect of pasture death on RRP during dry warm periods was investigated. Air-dry Joel soil $(<2 \mathrm{~mm})$ which had previously been under pasture for 15 years was pre-leached in a column to simulate the $\mathrm{P}$ status of the soil at the end of winter as in the previous experiment. The soil was removed from the column and divided into two sections, namely a control and a pasture death treatment. The equivalent of $7 \mathrm{tha}^{-1}$ of dry lucerne chaff was added to the pasture death treatment and mixed throughout the soil. Both treatments were incubated as described previously (no water was added, i.e. both treatments dried out completely) and were subsampled at times equivalent to $3,7,122$ and 170 days at $27.9^{\circ} \mathrm{C}$, and the RRP was determined.

\section{Experiment 6. Field Measurements}

\section{Site description}

The field work was carried out approximately $140 \mathrm{~km}$ south-west of Perth, Western Australia, with a climate as described previously. The soils were Bassendean sands, which included the Gavin series on the upper slopes and the Joel series in the lower regions. The site had been under pasture for over 15 years and had received annual applications of superphosphate, supplying $P$ at an average rate of $13 \mathrm{~kg} \mathrm{P} \mathrm{ha}{ }^{-1}$. The site was flat to gently sloping $\left(<0.6^{\circ}\right)$ and was under a mixed pasture of grasses (Lolium spp.), capeweed (Arctotheca calendula) and clover (Trifolium subterraneum L.) of which the grasses contribute about $60 \%$ of the biomass. Pasture growth did not respond to $\mathrm{P}$ applications. The area of approximately 15 ha was divided into plots which included one control, one fertilized in early July with superphosphate and one fertilized in mid-September with superphosphate. Ordinary superphosphate was applied to the fertilized plots at a rate of $18 \mathrm{~kg} \mathrm{Pha}^{-1}$ in granulated form to the soil surface using a belt spreader. All plots received $80 \mathrm{~kg} \mathrm{ha}^{-1}$ of potash in crystalline form and $120 \mathrm{~kg} \mathrm{ha}^{-1}$ of gypsum. The pasture was grazed by heifers. 


\section{Sampling}

The control plot and the plot fertilized in early July were divided equally into an upper section (control, plot 4; fertilized, plot 2) and lower section (control, plot 3; fertilized, plot 1) (for sampling purposes) to account for lateral flow of water. Soil samples were collected along two transects within each part of the plot. For these soils, McAlpine and Birch (1985) found that 20 samples were required to be $90 \%$ confident that the observed values of bicarbonate extractable and total $\mathrm{P}$ were within $\pm 10 \%$ of the true mean. Therefore, 20 samples were collected within each part of the plot at approximately weekly intervals from June 1984 to November 1984 and at approximately fortnightly intervals from November 1984 to June 1985 . Each soil was sampled to a depth of $20 \mathrm{~cm}$ and sectioned into intervals of $0-2,2-5,5-10$ and $10-20 \mathrm{~cm}$ and the 20 samples that were collected within each part of the plot at each interval were bulked. Rapidly released $\mathbf{P}$ was determined for each bulked sample. Pasture yield and $\mathbf{P}$ content of the pasture were determined on ungrazed areas of each treatment plot. Rainfall data were collected with a pluviometer and a rain gauge. Depth to the water table was measured by a series of tube wells.

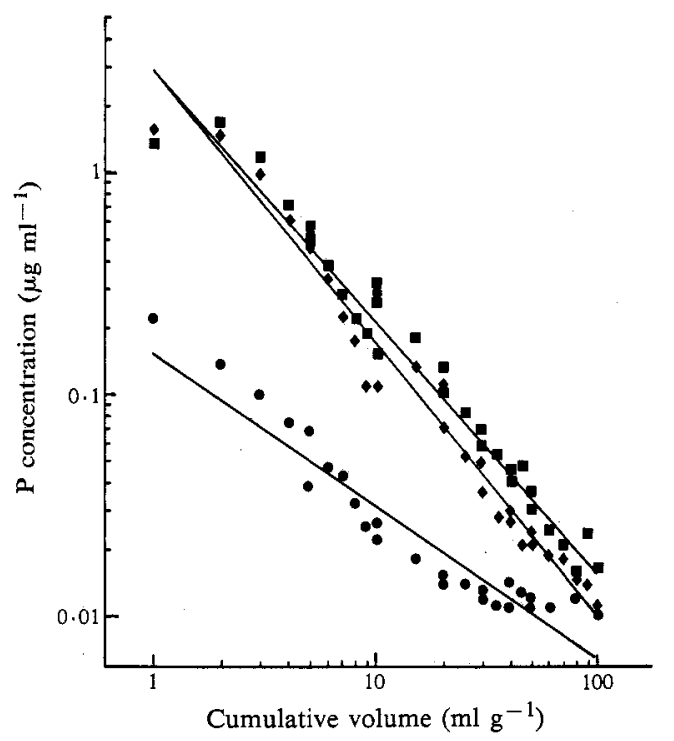

Fig. 1. Experiment 1: variation of the phosphorus concentration in sequential extracts of Joel soil incubated with superphosphate ( $\boldsymbol{G}$ ), lime-superphosphate ( $\bullet$ ) or coastal superphosphate (o).

\section{Results}

\section{Experiment 1. Sequential Desorption}

Phosphorus concentrations decreased logarithmically in the successive supernatants of the sequentially desorbed soils (Fig. 1). More $\mathbf{P}$ was desorbed from soils incubated with superphosphate and lime-superphosphate than soil incubated with coastal superphosphate. There was no significant difference $(P<0.05)$ between the slopes or intercepts of the fitted lines for superphosphate and lime-superphosphate, whereas the slope and intercept for coastal superphosphate were lower $(P<0.05)$.

\section{Experiment 2. Extent of Leaching}

At each level of pre-leaching, the $\mathbf{P}$ concentrations in the soil solution increased with increasing time (Fig. 2). The rate of increase was high for about 3 days and 
then declined until the $P$ concentrations no longer changed with time. The level to which the $P$ concentration in the soil solution increased at each time decreased with increased extent of pre-leaching.

\section{Experiment 3. Fertilizer Type, Application Rate and Time of Contact}

The addition of $\mathbf{P}$ fertilizers increased the concentration of $\mathbf{P}$ in the soil solution (Fig. 3). The concentrations increased with increasing application rate and were much higher for superphosphate than for coastal superphosphate. Increasing the time of
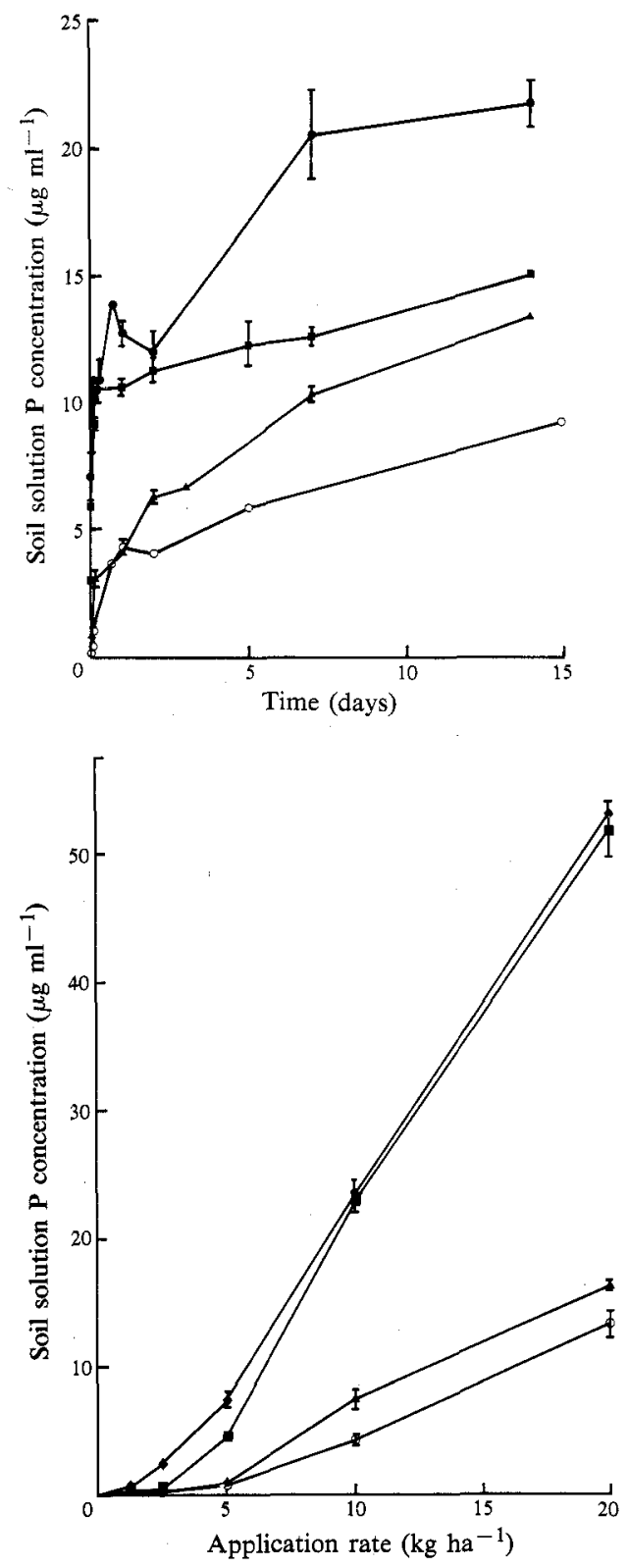

Fig. 2. Experiment 2: variation of soil solution phosphorus concentration with time after the equivalent of $0(\bullet)$, $50(\mathbf{a}), 200(\Delta)$ and $400(0) \mathrm{mm}$ of rain. Error bars show standard error of mean (SEM); SEM values less than the width of the points are not visible.

Fig. 3. Experiment 3: variation in soil solution phosphorus concentration with application rate $\left(\mathrm{kg} \mathrm{P}^{-1} 2.5 \mathrm{~cm}\right.$ depth) of superphosphate after 1 ( $\bullet$ and 14 (a) days of incubation and of coastal superphosphate after $1(\Delta)$ and 14 (o) days of incubation. Error bars as for Fig. 2. 
contact of the fertilizer with the soil from 1 to 14 days only marginally decreased the $P$ concentration, however, the decrease was greater for coastal superphosphate than for superphosphate.

\section{Experiment 4. Effect of Moisture on RRP after Continuous Leaching}

Rapidly released $\mathbf{P}$ increased with time in the control soil and in the soil incubated with additional moisture, after having a pre-treatment of leaching equivalent to winter rainfall $(850 \mathrm{~mm})$. In both treatments $R R P$ reached a constant level after approximately 100 days at $27.9^{\circ} \mathrm{C}$. The level of RRP reached in the presence of additional moisture (which simulates summer rainfall) was about three times that of the control soil (Fig. 4).
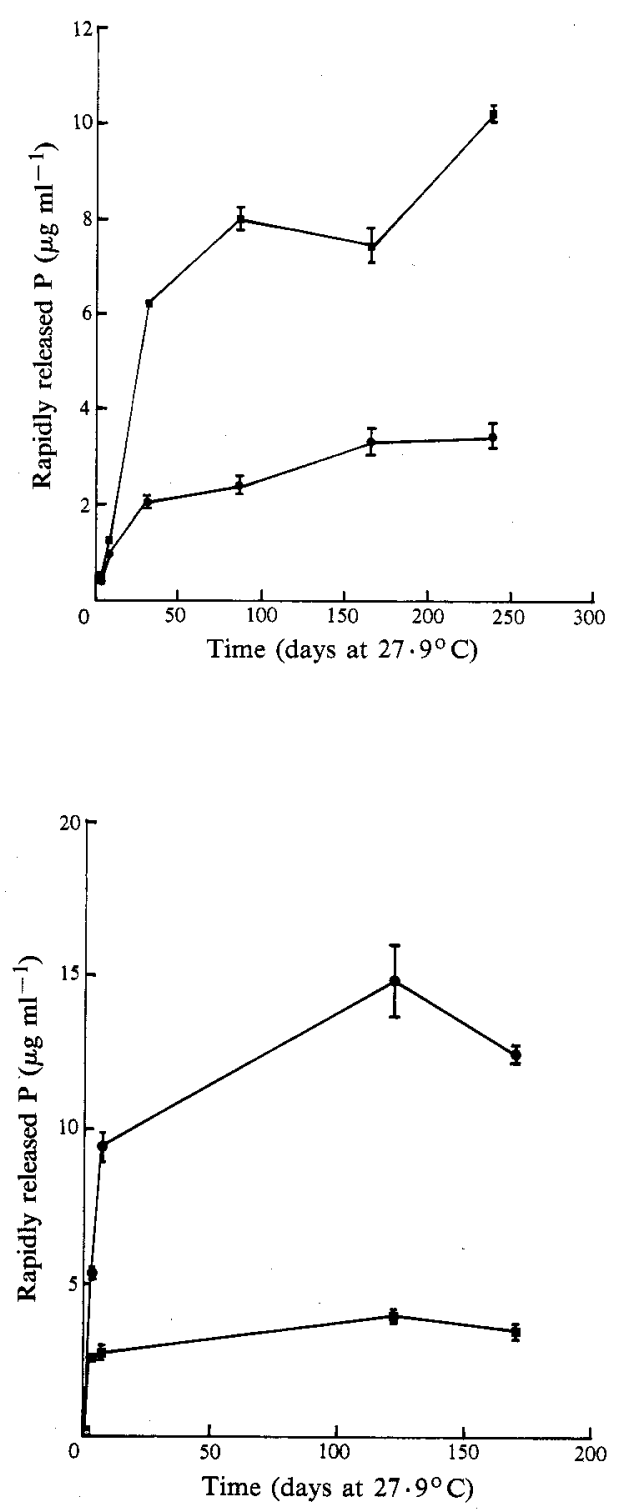

Fig. 4. Experiment 4: variation in rapidly released $P$ with time in the presence ( $\boldsymbol{\omega}$ ) and absence (•) of moisture after leaching with the equivalent of $850 \mathrm{~mm}$ of rain. Error bars as for Fig. 2 .
Fig. 5. Experiment 5: variation in rapidly released $P$ with time in the presence ( $)$ and absence ( $\square$ ) of $7 \mathrm{t} \mathrm{ha}-1$ of dry lucerne chaff after leaching with the equivalent of $850 \mathrm{~mm}$ of rain. Error bars as for Fig. 2. 


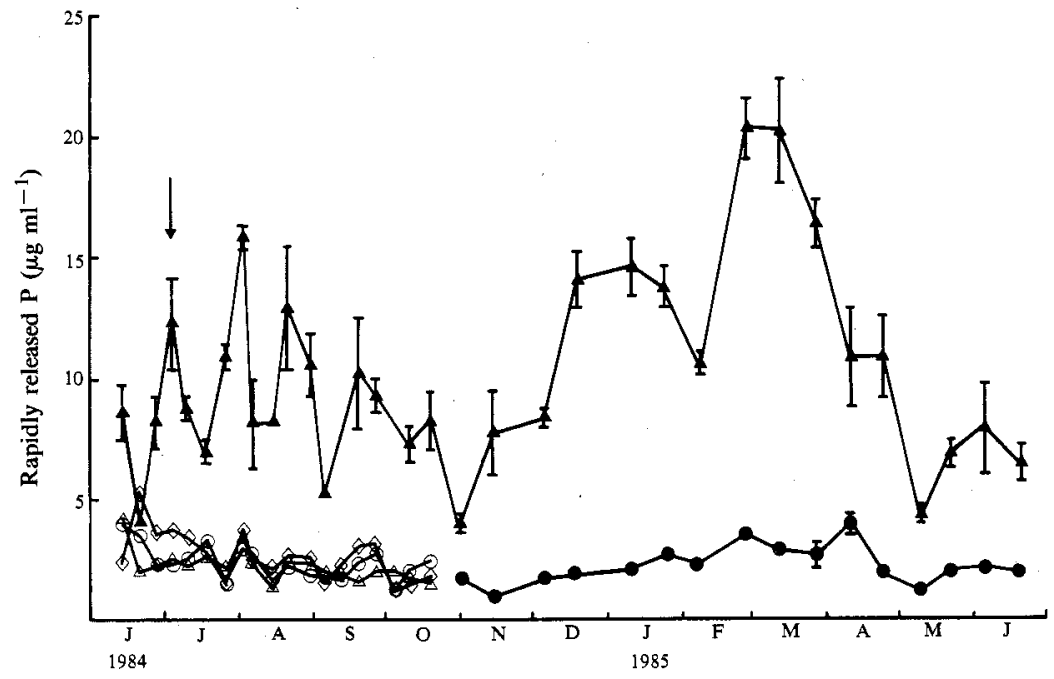

Fig. 6. Experiment 6: variation with time of rapidly released $P$ in the 0-2 (A), 2-5 ( $\Delta), 5-10(\diamond)$, 10-20 (O) and 2-20 (•) cm layers of the lower part of the plot fertilized with superphosphate in July. Error bars as for Fig. 2; arrow indicates P application.

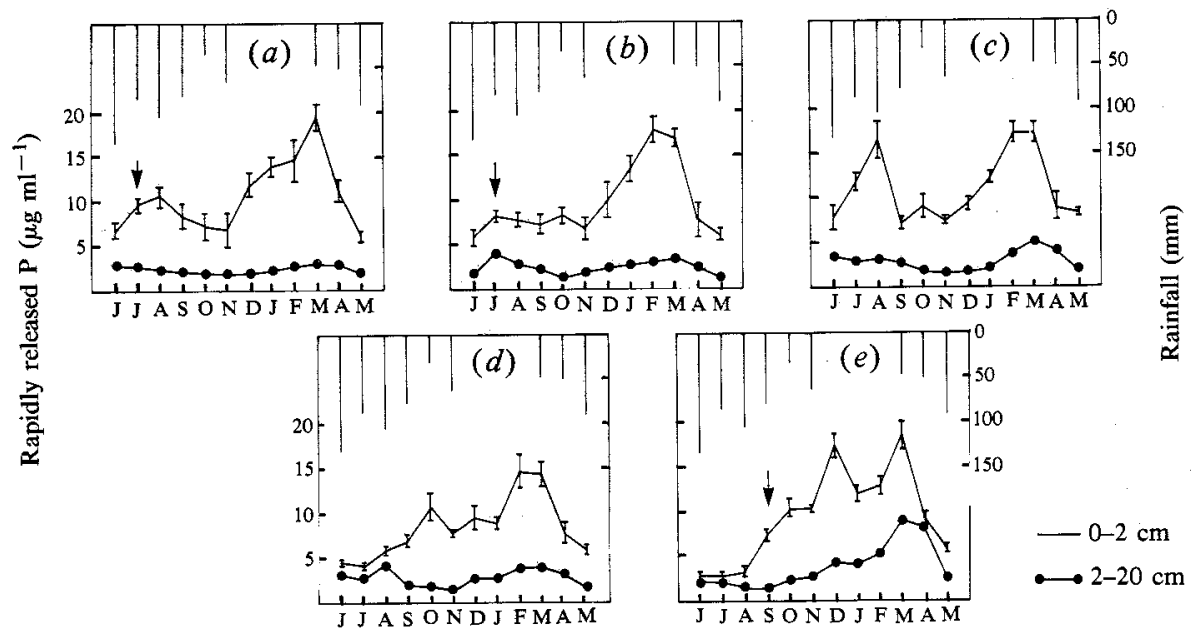

Fig. 7. Experiment 6: variation with time of the monthly mean of rapidly released $P$ in the $0-2$ and 2-20 cm layers of the lower $(a)$ and upper $(b)$ parts of the plot fertilized with superphosphate in July; the lower $(c)$ and upper $(d)$ parts of the plot receiving no superphosphate and the plot fertilized with superphosphate in September (e). Error bars as for Fig. 2; arrow indicates $\mathrm{P}$ application.

Table 2. Percentage of sampling dates for each plot at which rapidly released $P$ in the first layer is greater $(P<0.05)$ than that in the second layer

\begin{tabular}{lccccc}
\hline $\begin{array}{c}\text { Depths } \\
\text { compared }\end{array}$ & 1 & 2 & Plot number & 5 \\
\hline $2-5>5-10 \mathrm{~cm}$ & 42 & 61 & 53 & 72 & 64 \\
$5-10>10-20 \mathrm{~cm}$ & 53 & 39 & 47 & 39 & 41 \\
$2-5>10-20 \mathrm{~cm}$ & 53 & 89 & 63 & 94 & 68 \\
\hline
\end{tabular}




\section{Experiment 5. Effect of Adding Plant Material after Continuous Leaching on RRP}

Rapidly released $\mathbf{P}$ increased with time in the control soil and in the soil incubated with additional plant material, after having a pre-treatment of leaching equivalent to winter rainfall $(850 \mathrm{~mm})$. In both treatments RRP reached a constant level after approximately 100 days at $27.9^{\circ} \mathrm{C}$. The level of RRP reached in the presence of added plant material (which simulates pasture death) was about five times that of the control soil (Fig. 5).

\section{Experiment 6. Field Measurements}

Fertilization had no effect on pasture yield (superphosphate treatment, $3.64 \mathrm{t} \mathrm{ha}^{-1}$ dry weight; no treatment, 3.71 ) or $\mathbf{P}$ concentration of the pasture (both treatments, $0.307 \%$ ). Pasture death occurred in October on the upper sections of each treatment plot but was delayed until November on the lower sections because of the greater availability of moisture. Groundwater levels were closer to the soil surface in the lower regions than in the upper regions of the plots.

In all treatments, RRP in the $0-2 \mathrm{~cm}$ layer varied markedly with time and was higher $(P<0.05)$ than the levels determined lower down the soil profile (Figs 6 and 7). In general, RRP values in the lower layers of all treatments were significantly different from each other at $>50 \%$ of the sampling dates (Table 2). However, the differences were small in comparison with the differences between the $0-2 \mathrm{~cm}$ layer and the lower layers. In addition, since RRP in the lower layers did not vary much with time, the sampling regime was altered to include only the $0-2$ and $2-20 \mathrm{~cm}$ intervals after the first 5 months of observations. Therefore, only the mean of RRP of the three lower layers will be considered when discussed in the following sections. The monthly mean values of RRP which were calculated by integration showed the same trend as the individual values (Fig. 7).

Table 3. Level of significance at which rapidly released $P$ is higher in summer than in winter in the $0-2 \mathrm{~cm}$ layer

n.s., not significant

\begin{tabular}{cccccc}
\hline $\begin{array}{c}\text { Season } \\
\text { designation }\end{array}$ & 1 & 2 & 3 & 4 & 5 \\
\hline May-Oct. $v$. Nov.-April & $<0.01$ & $<0.01$ & n.s. & $<0.01$ & $<0.01$ \\
June-Aug. $v$. Dec.-Feb. & $<0.05$ & $<0.01$ & n.s. & $<0.01$ & $<0.01$ \\
\hline
\end{tabular}

In both fertilized and unfertilized plots, RRP in the $0-2 \mathrm{~cm}$ layer tended to increase after the winter and spring rains diminished and then decreased after the rain commenced again at the end of summer. Rapidly released $P$ in the $0-2 \mathrm{~cm}$ layer was always greater than $3 \mu \mathrm{g} \mathrm{ml}^{-1}$ (i.e. $2 \%$ of the annual application rate for the region), which is equivalent to approximately $0.3 \mathrm{~kg} \mathrm{P} \mathrm{ha}^{-1}$ and indicates that the potential for the soil to lose $P$ is always quite high.

When summer is designated as November-April or as December-February inclusive, RRP levels are higher $(P<0.05)$ in the summer months than in the corresponding winter months for all treatments except for the lower section of the unfertilized plot (Table 3).

There was no consistent change in RRP with increasing rainfall within the first wet season, although the wet season was well under way when sampling began. There 
were no statistically significant differences in RRP in the $0-2 \mathrm{~cm}$ layer due to fertilizer application. In fact, RRP levels for the lower section of the unfertilized plot (3) were higher than those of the fertilized plot (1) (Table 4). Rapidly released $P$ in the lower section of the unfertilized plot (3) was greater $(P<0.01)$ than RRP in the upper section (4), presumably because of lateral flow of water transferring RRP from further upslope. No effect of lateral flow was observed in the fertilized plots $(1,2)$.

Rapidly released $\mathrm{P}$ levels increased steadily over the period November-March (Fig. 7). There were no significant differences between the plots over the summer period. Fertilizer additions to the soil in winter had no effect on RRP during the following summer.

Table 4. Level of significance at which rapidly released $P$ in the $0-2 \mathrm{~cm}$ layer differs between plots during winter

n.s., not significant. Values in parentheses denote plots with higher concentrations

\begin{tabular}{|c|c|c|c|}
\hline \multirow{2}{*}{$\begin{array}{c}\text { Plots } \\
\text { compared }\end{array}$} & \multirow{2}{*}{$\begin{array}{c}\text { Variable that } \\
\text { differs between plots }\end{array}$} & \multicolumn{2}{|c|}{ Winter designation } \\
\hline & & May-October & June-August \\
\hline 1,3 & $\begin{array}{l}\text { Addition of fertilizer } \\
\text { (lower slope) }\end{array}$ & $<0.1$ (3) & $<0.05(3)$ \\
\hline 2,4 & $\begin{array}{l}\text { Addition of fertilizer } \\
\text { (upper slope) }\end{array}$ & n.s. & n.s. \\
\hline 1,2 & $\begin{array}{l}\text { Lateral flow in presence } \\
\text { of fertilizer }\end{array}$ & n.s. & n.s. \\
\hline 3,4 & $\begin{array}{l}\text { Lateral flow in absence } \\
\text { of fertilizer }\end{array}$ & $<0.01(3)$ & $<0.01(3)$ \\
\hline
\end{tabular}

The changes in RRP in the $2-20 \mathrm{~cm}$ layer were negligible in comparison to changes in the surface layer $(0-2 \mathrm{~cm})$. There was limited evidence of downward movement of $P$ from the surface layer to the subsurface layer in the upper section of the plot fertilized in July. Rapidly released $P$ levels in the month after fertilization for the 2-20 cm layer of the upper section of the fertilized plot were greater $(P<0.05)$ than RRP levels in the lower section. Depth to groundwater over the same period ranged from $0-10 \mathrm{~cm}$ in the lower section of the fertilized plot and ranged from $20-110 \mathrm{~cm}$ in the upper section.

\section{Discussion}

The laboratory and field data support the hypothesis that the potential for $\mathbf{P}$ to be lost from sandy soils depends upon previous as well as current management practices and environmental conditions. Even though the laboratory studies evaluated individual factors under controlled conditions, they acted as a guide to the interpretation of the field data. Laboratory studies indicated that $\mathrm{P}$ in the soil solution decreased with continuous removal from it by 'continuous leaching' (sequential desorption). In the field, however, it was not always possible to correlate decreases in RRP with rainfall events because of high $P$ levels in the soil and the logistical difficulties associated with sample collection immediately after a rainfall event. Changes in the soil solution $\mathbf{P}$ concentration may only be small when the level of RRP is high because the $P$ lost to drainage is only a small percentage of the total $\mathbf{P}$. Nevertheless, the data in 
Figs 6 and 7 illustrate that RRP does decrease with time during the wet season, presumably because the rate of replenishment cannot keep up with the rate of loss. In the laboratory studies, the presence of soil moisture or the incorporation of lucerne chaff increased RRP in soils that had been pre-leached with the equivalent of $850 \mathrm{~mm}$ of rainfall. Presumably, the previous leaching had disturbed the equilibrium between $P$ in the soil solution and in particulate forms. The addition of moisture increased the amount of $\mathbf{P}$ released into the soil solution whereas, by incorporating lucerne chaff, both inorganic and organic $P$ were added to the soil in a similar manner to the re-cycling of $P$ due to the death of annual pasture. Similarly, RRP increased during the dry season in the field.

In addition to rainfall pattern and fertilizer management, the estimation of $P$ losses in the field were found to depend on sampling depth, water flow path and background $P$ levels. In the soils monitored in the field, the majority of RRP was concentrated in the upper $2 \mathrm{~cm}$ of the soil (Figs 6 and 7); presumably because fertilizers were broadcast, runoff was a major flowpath of water and plants re-cycle $\mathbf{P}$ to the surface layer after senescence. If a larger volume of soil had been sampled (e.g. $0-10 \mathrm{~cm}$ ), then many of the changes in the $0-2 \mathrm{~cm}$ layer would not have been detected as they would have been diluted by a larger soil volume. This may have been the case for other workers who have looked for consistent seasonal changes in soil P levels. For example, Friesen et al. (1985) sampled $7.5 \mathrm{~cm}$, Saunders and Metson (1971) sampled $5 \mathrm{~cm}$, Blakemore (1966) sampled $10 \mathrm{~cm}$, Gupta and Rorison (1975) sampled $4 \mathrm{~cm}$, Garbouchev (1966) sampled $15 \mathrm{~cm}$ and Sharpley (1985) sampled $5 \mathrm{~cm}$.

The mechanism of water movement appears to be an important factor in determining the extent of $\mathbf{P}$ losses and changes in RRP with depth. Downward leaching and lateral flow at depth prolong the residence time of $P$ in the soil and may give plants more opportunity to use it, thereby decreasing $P$ losses. In addition, downward leaching mixes the $\mathbf{P}$ through a greater volume of soil which may minimize the detected differences in P levels in consecutive soil layers. Runoff and lateral flow in the upper few $\mathrm{cm}$ of the soil tend to confine $\mathbf{P}$ from broadcast fertilizer to the upper layer which decreases its contact with soil and plant roots and hence may increase $P$ losses.

Changes in RRP in the surface layer due to the addition of superphosphate were masked by the high background levels of $P$ already present (Fig. 7). Also, the fertilizer $\mathbf{P}$ may have been lost from the surface layer almost immediately after application and before the next sampling date. This appears to have occurred in the upper section of the plot fertilized in July (Fig. $7 b$ ).

A possible annual cycle of $P$ in sandy soils in a mediterranean climate may be postulated by considering the laboratory and field data in combination (Fig. 8). Experiments 1-5 suggested that, during winter, the amount and distribution of rainfall and the solubility and rate at which fertilizers are applied are the main determinants controlling the magnitude of $\mathbf{P}$ losses to drainage and plants. From experiment 1 , we may hypothesize that after the initial rains have wet the soil at the beginning of winter, there is a large amount of $\mathbf{P}$ in the soil solution [( $a)$ in Fig. 8]. This soil solution $\mathbf{P}$ is lost to drainage following further rain [(b) in Fig. 8]. This disturbs the overall equilibrium between the pools, so rapidly released $\mathrm{P}$ moves to the soil solution to balance the loss. The rate of release of $\mathbf{P}$ to the soil solution from particulate sources is not as fast as the rate of $P$ removal from it by drainage. Therefore, the soil solution becomes more and more depleted and losses decrease as rainfall continues. 


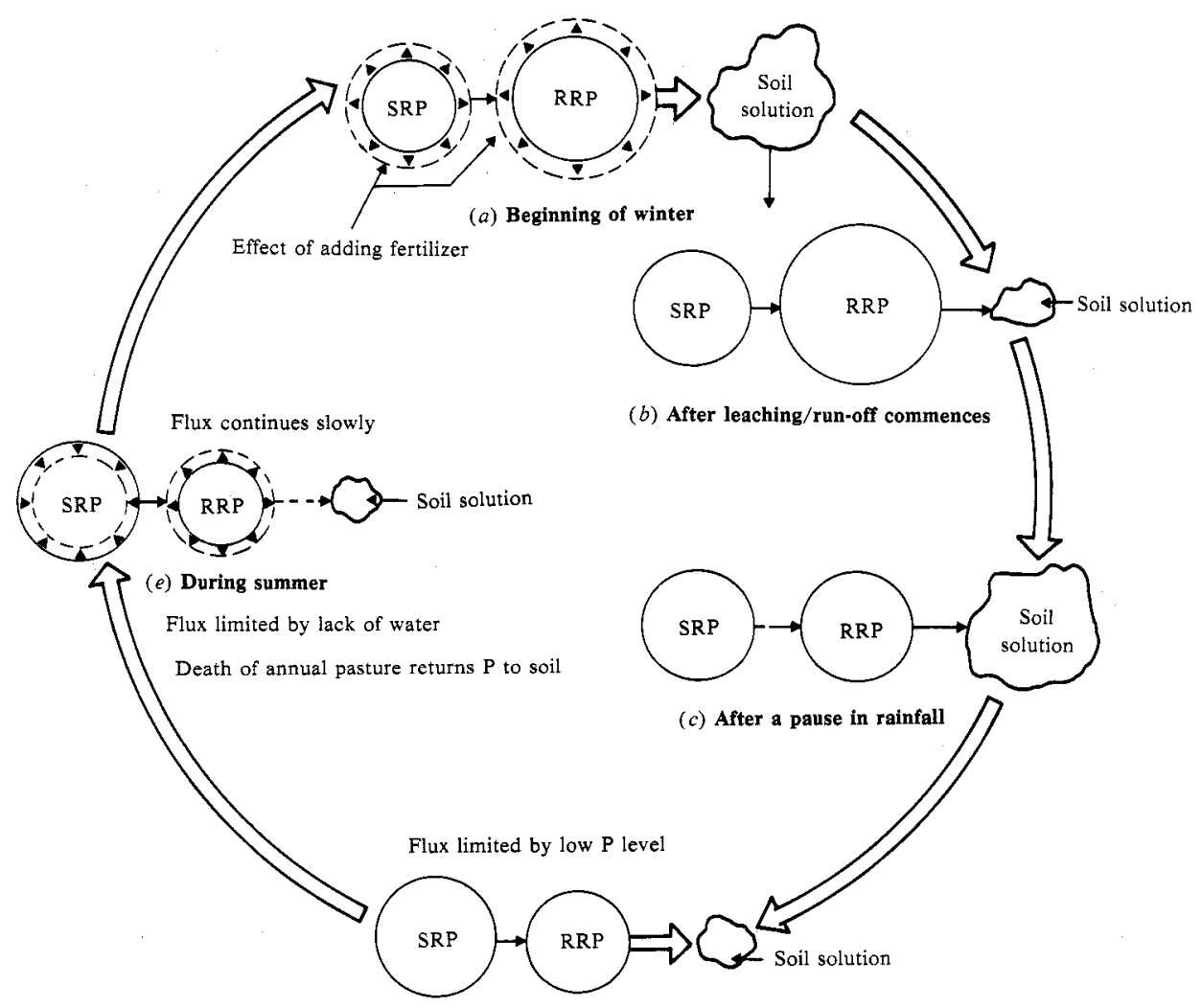

(d) End of winter

Fig. 8. Schematic representation of seasonal changes of slowly released phosphorus (SRP), rapidly released phosphorus (RRP) and soil solution phosphorus.

Experiment 2 indicates that release of $\mathbf{P}$ into the soil solution from particulate sources continues during any pauses in the rainfall, even though drainage temporarily ceases. Consequently, when drainage recommences with the next rainstorm, more $\mathbf{P}$ is lost than would be the case with continuous rain because of the release of $P$ into the soil solution during the pause [ $(c)$ in Fig. 8]. The release of $P$ into the soil solution decreases as the extent of previous leaching increases (i.e. as the season progresses). At the end of winter, therefore, the soil solution and the pool of rapidly released $\mathbf{P}$ are both depleted because of prolonged losses to drainage, plant uptake and the continual release of $P$ into the soil solution from particulate sources [ $(d)$ in Fig. 8]. Experiments 4,5 and 6 suggest that during the following summer the level of rapidly released $P$ increases (reflected by the increase in soil solution $P$ levels), presumably due to the replenishment from slowly released sources. The rate and extent of replenishment is increased by occasional summer storms that wet the soil, but not sufficiently to cause drainage from the soil. The death of annual pasture late in spring and the addition of $\mathbf{P}$ fertilizers in late autumn add $\mathbf{P}$ to the soil. Consequently, at the beginning of the next wet season, the pool of rapidly released $P$ has built up again and is available to supply the soil solution with $P$ once the first rains begin. 
The wet phase components of the hypothetical cycle [(a)-(d) in Fig. 8] could be tested in the field by using rainfall simulators to control the distribution and amount of rainfall. This would enable soil sampling immediately before and after rainfall events so that $\mathbf{P}$ in the soil solution could be measured. The hypothesis concerning the drier phases of the cycle [(e) in Fig. 8] could be tested by controlling the senescence of pasture plants and measuring RRP before and after pasture death.

\section{Acknowledgments}

The authors wish to thank the Department of Conservation and Environment, Perth, W.A. for funding this research and J. Evangolista, V. Cox and K. Pritchard for technical assistance.

\section{References}

Berkheiser, V. E., Street, J. J., Rao, P.S.C., and Yuan, T. L. (1980). Partitioning of inorganic orthophosphate in soil-water systems. In 'CRC Critical Review on Environmental Control'. pp. 179-224. (Gainesville, Florida.)

Bettenay, E., McArthur, W. M., and Hingston, F. J. (1960). The soil associations of part of the Swan Coastal Plain, Western Australia. CSIRO Aust. Soils and Land Use Ser. No. 35.

Birch, P. B. (1982). Phosphorus export from coastal plain drainage to the Peel-Harvey Estuarine system, Western Australia. Aust. J. Mar. Freshwater Res. 33, 23-32.

Blakemore, M. (1966). Seasonal changes in the amounts of phosphorus and potassium dissolved from soils by dilute calcium chloride solutions. J. Agric. Sci. 66, 139-46.

Castellan, G. W. (1970). 'Physical Chemistry.' (Addison-Wesley: Massachusetts.)

Enfield, C. G., and Ellis, R. (1983). The movement of phosphorus in soil. In 'Chemical Mobility and Reactivity in Soil Systems'. SSSA Special Publ. No. 11.

Friesen, D. K., Blair, G. J., and Duncan, M. (1985). Temporal fluctuations in soil test values under permanent pasture in New England, N.S.W. Aust. J. Soil Res. 23, 181-93.

Garbouchev, I. P. (1966). Changes occurring during a year in the soluble phosphorus and potassium in soil under crops in rotation experiments at Rothamsted, Woburn and Saxmundham. $J$. Agric. Sci. 66, 399-412.

Gillman, G. P. (1970). A centrifuge method for obtaining soil solution. CSIRO Aust. Div. Soils, Rep. No. 16.

Gillman, G. P. (1973). Studies on some deep sandy soils in Cape York Peninsula, North Queensiand. 3. Losses of applied phosphorus and sulphur. Aust. J. Exp. Agric. Anim. Husb. $13,418-22$.

Gupta, P. L., and Rorison, I. H. (1975). Seasonal differences in the availability of nutrients down a podzolic profile. J. Ecol. 63, 521-34.

Hingston, F. J. (1959). The loss of applied phosphorus and sulphur from soils under pasture in Western Australia. J. Aust. Inst. Agric. Sci. 25, 209-13.

Hodgkin, E. P., Birch, P. B., Black, R. E., and Humphries, R. B. (1980). The Peel-Harvey Estuarine System Study (1976-80). Dept. of Conservation and Environment, Perth, Rep. No. 9.

John, M. K. (1970). Colorimetric determination of phosphorus in soil and plant materials with ascorbic acid. Soil Sci. 109, 214-20.

McAlpine, K. W., and Birch, P. B. (1985). Spatial variability of total and bicarbonate extractable phosphorus and its relationship to sample size in two soils of the Swan Coastal Plain, Western Australia. Dept. of Conservation and Environment Bull. No. 201, Perth.

McArthur, W. M., and Bettenay, E. (1960). The development and distribution of the soils of the Swan Coastal Plain, Western Australia. CSIRO Aust., Soil Publ. No. 16.

Neller, J. R. (1946). Mobility of phosphates in sandy soils. Soil Sci. Soc. Am. Proc. 11, 227-30. 
Saunders, W. M. H., and Metson, A. J. (1971) Seasonal variation of phosphorus in soil and pasture. N.Z. J. Agric. Res. 14, 307-28.

Sharpley, A. N. (1985). Phosphorus cycling in unfertilized and fertilized agricultural soils. Soil Sci. Soc. Am. J. 49, 905-11.

Yeates, J. S., Deeley, D. M., Clarke, M. F., and Allen, D. (1984). Modifying fertilizer practices. J. Agric. West. Aust. 25, 87-91. 